\title{
IDENTIFIKASI FORMALIN PADA IKAN ASIN YANG DIPERJUALBELIKAN DI PASAR DAYA MAKASSAR
}

\author{
Mawar \\ Jurusan Analis Kesehatan Poltekkes Kemenkes Makassar
}

\begin{abstract}
ABSTRAK
Penelitian ini bertujuan untuk mengidentifikasi formalin pada ikan asin yang diperjual belikan di Pasar Daya Makassar. Jenis penelitian ini adalah penelitian obsevasional, yakni pengamatan terhadap ada-tidaknya formalin pada ikan asin yang diperjualbelikan di Pasar Daya Makassar. Penelitian dilakukan pada bulan Agustus 2017 yang dilaksanakan di laboratorium Jurusan Analis Kesehatan Poltekkes Kemenkes Makassar. Sampelnya adalah 8 jenis ikan asin yang diperjual belikan di Pasar Daya Makassar. Hasil penelitian menunjukan bahwa 2 dari 8 sampel ikan asin yang diperjualbelikan di Pasar Daya mengandung formalin.
\end{abstract}

Kata Kunci : Formalin dan Ikan Asin

\section{PENDAHULUAN}

Pangan merupakan salah satu faktor yang langsung berpengaruh terhadap kondisi kesehatan manusia. Pangan yang aman, bermutu dan bergizi dibutuhkan tubuh untuk menunjang aktivitas. Sebaliknya, pangan yang tidak memenuhi standar keamanan, mutu dan gizi akan membahayakan kesehatan tubuh. Pemilihan pangan sebelum dikonsumsi sangat penting agar terhindar dari produk pangan yang tidak memenuhi standar serta dapat membahayakan kesehatan (BPOM, 2002).

Salah satu yang perlu diperhatikan dalam memilih pangan adalah bahan tambahan yang digunakan dalam produk pangan. Pangan yang aman harus menggunakan bahan tambahan yang oleh pemerintah dinyatakan aman untuk digunakan pada pangan. Pedagang yang tidak mengerti atau tidak peduli terhadap keamanan pangan adakalanya menggunakan bahan yang tidak diperbolehkan untuk ditambahkan dalam pangan. Pangan inilah yang perlu diwaspadai dan dihindari untuk dikonsumsi (BPOM, 2002).

Salah satu bahan yang dilarang digunakan untuk pangan adalah formalin. Formalin sangat berbahaya bagi kesehatan, tidak hanya menimbulkan efek jangka pendek atau akut -misalnya mual, muntah, diare, dsb, namun juga menimbulkan efek jangka panjang atau kronis, misalnya luka pada ginjal, paru, dan kanker (BPOM, 2002).

Formaldehid atau formalin dilarang digunakan sebagai bahan pengawet berdasarkan Permenkes Rl No.235/Menkes/Per/VI/79 dan yang termasuk dalam bahan tambahan makanan yang dilarang digunakan dalam makanan berdasarkan peraturan Menteri Kesehatan Rl No. 772/Menkes/Per/XI/88 (BPOM, 2002).

Makanan merupakan kebutuhan pokok manusia karena di dalamnya 
mengadung nutrisi yang diperlukan, antara lain : untuk pertumbuhan badan, memelihara dan memperbaiki jaringan tubuh yang telah tua atau rusak, diperlukan untuk proses terjadi dalam tubuh, diperlukan untuk berkembang biak, menghasilkan energi untuk dapat melakukan aktivitas (Sartono, 2015).

Gaya hidup rnanusia masa kini dengan mobilitas yang cukup tinggi. menuntut makanan serba instan dan tahan lama, tuntutan ini melahirkan konsekuensi yang bisa saja membahayakan, karena bahan kimia semakin lasim digunakan untuk mengawetkan makanan.

Berdasarkan hasil investigasi dan pengujian laboratorium yang dilakukan balai besar Pengawasan Obat Makanan (POM) di Jakarta, ditemukan sejumlah produk pangan seperti ikan asin, mie basah, dan tahu yang memakai formalin sebagai pengawet. Dari hasil pengujian Balai Besar POM di Jakarta pada November - Desember 2005 terhadap 98 sampel produk pangan yang dicurigai rnengandung formalin, 56 sampel diantaranya dinyatakan positif mengandung formalin. Berbagai produk pangan itu diambil dari sejumlah pasar tradisional dan supermarket di Wilayah Jakarta, diantaranya pasar Muara Angke, hasilnya, dari 23 sampel mi basah, 15 diantaranya tercemar formalin, dari 34 sampel aneka jenis ikan asin, 22 sampel diantaranya juga tercemar formalin $(64,7 \%)$. Sampel ikan asin yang positif berformalin itu anatar lain ikan asin, sange belah, ikan cucut, daging super, dan jambal roti. Selain itu, di makassar juga, BB-POM Makassar menemukan mie basah, tahu, bakso, dan ikan asin dari 117 sampel yang diperiksa, dinyatakan tidak memenuhi syarat karena mengandung formalin.

Bahan pangan sengaja diberi formalin agar lebih awet dan tidak mudah hancur. Formalin merupakan bahan kimia yang sangat berbahaya bagi kesehatan. Efek pada tubuh antara lain berupa iritasi pada saluran pernapasan, muntah-muntah, pusing dan terasa terbakar pada tenggorokan. Jika konsumsi terus menerus dalam jangka waktu lama, produk makanan yang mengandung formalin itu dapat menyebabkan kerusakan hati, jantung, otak, limpa, pankreas, sistem susunan syaraf pusat dan ginjal.

Berdasarkan fenomena diatas penulis tertarik untuk melakukan penelitian, tentang bahan pengawet makanan khususnya formalin pada ikan asin yang di jual di Kota Makassar khususnya di Pasar Daya Makassar. Tujuan penelitian adalah untuk mengidentifikasi formalin pada ikan asin yang diperjual belikan di Pasar Daya Makassar.

\section{METODE}

Jenis, tempat dan waktu penelitian

Jenis penelitian ini adalah penelitian observasional, yakni untuk mengamati ada-tidaknya formalin pada ikan asin yang diperjual belikan di Pasar Daya Makassar. Penelitian ini dilakukan pada bulan Agustus 2017, dilaksanakan pada laboratorium Jurusan Analis Kesehatan Poltekkes Makassar.

Populasi, Sampel, Alat dan Bahan Penelitian

Populasi adalah ikan asin yang di jual di Pasar Daya Makassar, sedangkan sampelnya adalah ikan asin yang diambil secara acak sebanyak 8 jenis. Peralatan yang 
dibutuhkan dalam penelitian ini adalah alat destilasi, Blender, Corong, Erlenmeyer, Gelas ukur, Hot Plat, Labu Iod $500 \mathrm{~mL}$, Labu ukur $50 \mathrm{~mL}$, Pipet volume $1 \mathrm{~mL}, 2 \mathrm{~mL}$, dan $20 \mathrm{~mL}$, Timbangan. Bahan Penelitian diantaranya Asam Phospat $\left(\mathrm{H}_{3} \mathrm{PO}_{4}\right)$ pekat, Aquadest, Asam Khlorida (HCL), Etanol 96\%, Fenilhidrazin $1 \%$, Ikan Asin (Sampel), $\mathrm{K}_{3}\left(\mathrm{Fe}(\mathrm{CN})_{6}\right)$ $1 \%$, Larutan formalin standar $10 \mathrm{ppm}$.

\section{Prosedur Kerja Penelitian}

Persiapan sampel:

Sampel (ikan asin) ditimbang sebanyak 40 gram, ditambahkan 100 $\mathrm{mL}$ aquadest. Dihancurkan, kemudian ditambahkan $\mathrm{H}_{3} \mathrm{PO}_{4}$ pekat sebanyak 2,5 mL. Dimasukan ke dalam labu Iod, kemudian didestilasi. Destilasi dilakukan sampai didapatkan destilat $10 \mathrm{~mL}$.

Menyiapkan larutan standar sebagai blanko positif:
$5 \mathrm{~mL}$ larutan standar formalin 10 ppm, dimasukan ke dalam labu ukur $100 \mathrm{~mL}$, kemudian ditambahkan dengan aquadest sampai tanda garis, sehingga konsentrasinya menjadi 0,05 ppm. $10 \mathrm{~mL}$ larutan yang sudah diencerkan ditambahkan fenilhidrazin $1 \%$ sebanyak $2 \mathrm{~mL}$. Ditambahkan $\mathrm{K}_{3}\left(\mathrm{Fe}(\mathrm{CN})_{6}\right) \quad 1 \%$ sebanyak $1 \mathrm{~mL}$. Kemudian ditambahkan HCL sebanyak $5 \mathrm{~mL}$. Larutan akan berwarna merah (Blanko).

Melakukan pemeriksaan sampel:

$10 \mathrm{~mL}$ destilasi diambil, kemudian ditambahkan fenilhidrazin $1 \%$ sebanyak $2 \mathrm{~mL}$. Ditambahkan $\mathrm{K}_{3}\left(\mathrm{Fe}(\mathrm{CN})_{6}\right) 1 \%$ sebanyak $1 \mathrm{~mL}$ dan HCL pekat $5 \mathrm{~mL}$. Adanya formalin ( $\mathrm{HCHO})$ ditandai dengan perubahan menjadi merah dengan pemeriksaan terhadap blanko.

\section{HASIL}

Tabel.1

Deteksi formalin pada 8 jenis ikan asin yang diambil dari Pasar Daya Makassar sebagai berikut :

\begin{tabular}{cclc}
\hline No. Lab & Kode Sampel & Parameter & Hasil \\
\hline 3864 & 1 & Formalin & Negatif \\
3865 & 2 & & Negatif \\
3866 & 3 & & Negatif \\
3867 & 4 & & Negatif \\
3868 & 5 & & Positif \\
3869 & 6 & & Negatif \\
3870 & 7 & & Positif \\
3871 & 8 & & Negatif \\
\hline
\end{tabular}

\section{PEMBAHASAN}

Dalam penelitian ini, sampel yang digunakan adalah sampel ikan asin yang diperjualbelikan oleh pedagang di Pasar Daya Makassar. Sampel tersebut diambil kemudian dilakukan penelitian di Laboratorium
Jurusan Analis Kesehatan Poltekkes Kemenkes Makassar dengan tujuan yaitu untuk mengetahui ada tidaknya bahan pengawet jenis Formalin dalam sampel tersebut dengan menggunakan cara destilasi. Hasil dari destilasi ditambahkan dengan fenilhidrazin 
$1 \%$, kalium ferisianida $1 \%$, dan asam klorida pekat, adanya formalin ditandai dengan timbulnya warna merah sebagai hasil pereaksi antara formalin dengan pereaksi tersebut.

Dari hasil penelitian yang di lakukan, ditemukan hasil positif pada kode sampel 5 dan 7, hal ini menunjukan bahwa ikan asin yang di jual disekitar pasar daya Kota Makasar 20\% mengandung bahan pengawet jenis formalin. Hal ini dikarenakan kurangnya tingkat kesadaran pedagang dan pengusaha makanan dalam menjaga keamanan makanan. jika makanan kita mengandung bahan pengawet jenis formalin dalam jangka waktu pendek tidak akan mengalami keracunan, akan tetapi setelah makanan yang mengandung bahan pengawet jenis formalin tersebut selalu di komsumsi maka akan berubah sifatnya menjadi karsinogen yaitu dapat memicu terjadinya kanker hati.

Banyaknya formalin yang di temukan sebagai bahan pengawet dalam berbagai macam makanan mengakibatkan pengawasan semakin di perketat, karena formalin bersifat karsinogenik yang akan menyebabkan gangguan kesehatan, diantaranya tenggorokan terasa panas dan memicu terjadinya kanker yang pada akhirnya akan mempengaruhi organ tubuh lainya.

\section{KESIMPULAN}

Berdasarkan hasil penelitian dan pembahasan di atas maka dapat disimpulkan bahwa 2 dari 8 sampel ikan asin yang diperjualbelikan di Pasar Daya menggunakan bahan pengawet jenis formalin.

\section{DAFTAR PUSTAKA}

Amiruddin, A. dkk. 1992. Kamus Kimia Organik. Jakarta: Depdikbud.

Bacle 2010. Ilmu Pangan (UI - Press) Djarijah, A.S., 2011. Ikan Asin. Kanisius, Yogyakarta.

Fesenden R.J. dan Fenssenden J.S. 2003. Kimia Organik. Edisi Kedua. Jakarta. Erlangga

Indiasari, Lusiana，2016. Waspadai bahan kimia lain dalam makanan.www.google.com

RI Departemen Kesehatan, 2002. Farmakope Indonesia. Edisi Ketiga, Direktorat Jendral Kepengawasan Obat dan Makanan. Jakarta.

Sartono. 2015. Drs. Racun dan Keracunan. Widia Medika. Jakarta.

SMAK, 2015. Kimia Air. Pusat Pendidikan Tenaga Kesehatan Departemen Kesehatan. Jakarta.

Siswanto, 2010. Toksikologi Indiustri. Balai Hiperkes Dan Keselamatan Kerja, Departemen Tenaga Kerja, Makassar.

Soekidjo Notoatmodjo, Dr. 2015. Metodologi Penelitian Kesehatan. Renika Cipta. Jakarta.

Sugiono, S., 2012. Statistika Untuk Penelutian. Alfabeta, Bandung.

Sukesi, 2016. Cara Baru Kurangi Kadar Formalin. Diunduh tanggal 5 mei 2017 dari http://www.its.ac.id/tanggapa nberita.php?Newsid=2689$29 \mathrm{k}$.

Winarmo. 2012. Kimia Pangan Gizi. PT. Gramedia Utama. Jakarta. 
Jurnal Media Analis Kesehatan, Vol. 8, No.2, November 2017 http://journal.poltekkes-mks.ac.id/ojs2/index.php/mediaanalis e-ISSN : 2621-9557

p-ISSN : 2087-1333

Winarmo. F.G. dan Rahayu T.S.

2014. Bahan Tambahan

Makanan dan Kontaminasi.

Jakarta. Pustaka Sianar

Harapan. 